\title{
Granuloma annulare mimicking cutaneous sarcoidosis.
}

Mariem Daldoul ${ }^{1}$, Mouna Korbi ${ }^{2}$, Hayet Akkari ${ }^{1}$, Badreddine Sriha ${ }^{3}$, Hichem Belhadjali ${ }^{1}$, and Jameleddine Zili ${ }^{1}$

${ }^{1}$ Fattouma Bourguiba University Hospital of Monastir

${ }^{2}$ Fattouma Bourguiba University Hospital, University of Medicine, University of Monastir

${ }^{3}$ Farhat Hached University Hospital of Sousse

February 18, 2022

\begin{abstract}
Granuloma annulare (GA) is a benign skin granulomatous, with, usually, unknown cause. Few challenging cases of GA have been reported in the literature mimicking sarcoidosis. We describe a rare clinical presentation of GA mimicking cutaneous sarcoidosis.
\end{abstract}

\section{Hosted file}

Main document..doc available at https://authorea.com/users/461262/articles/556984-granulomaannulare-mimicking-cutaneous-sarcoidosis

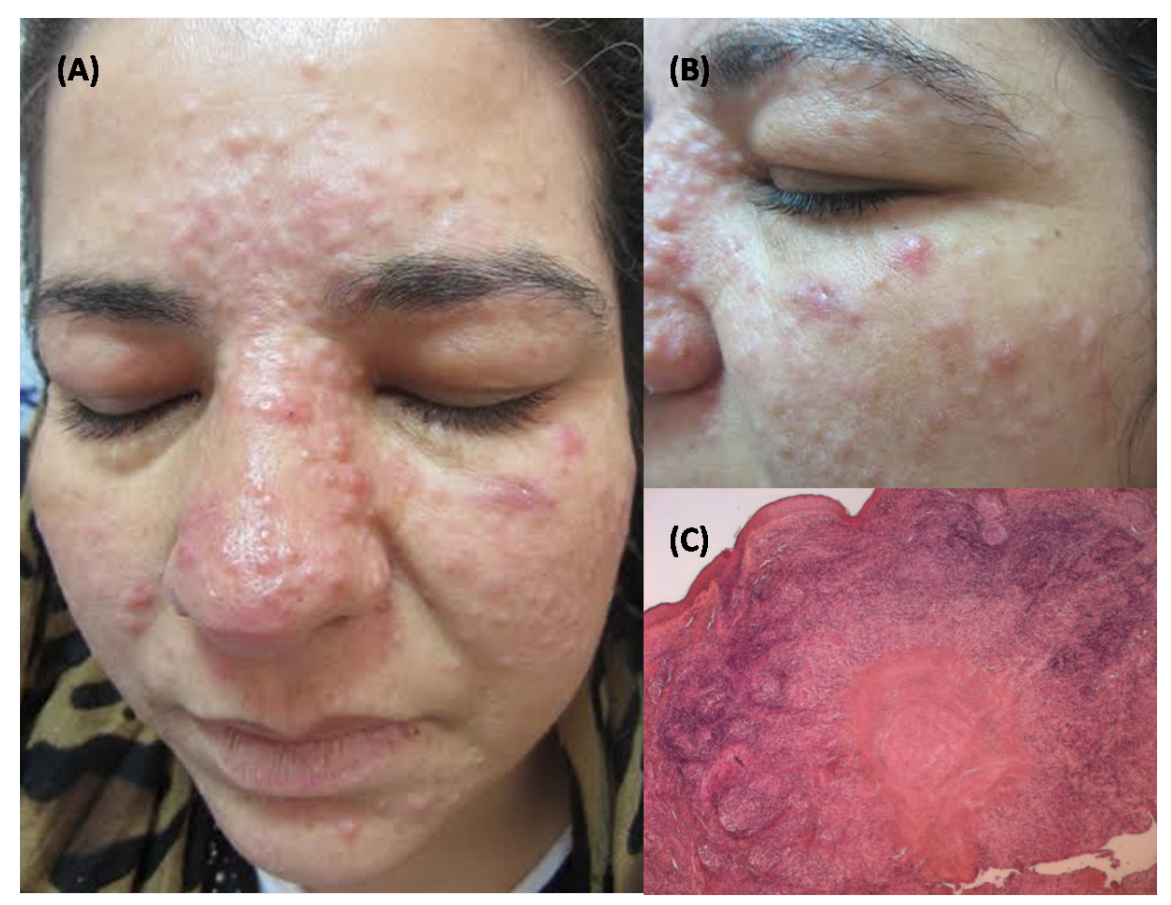

